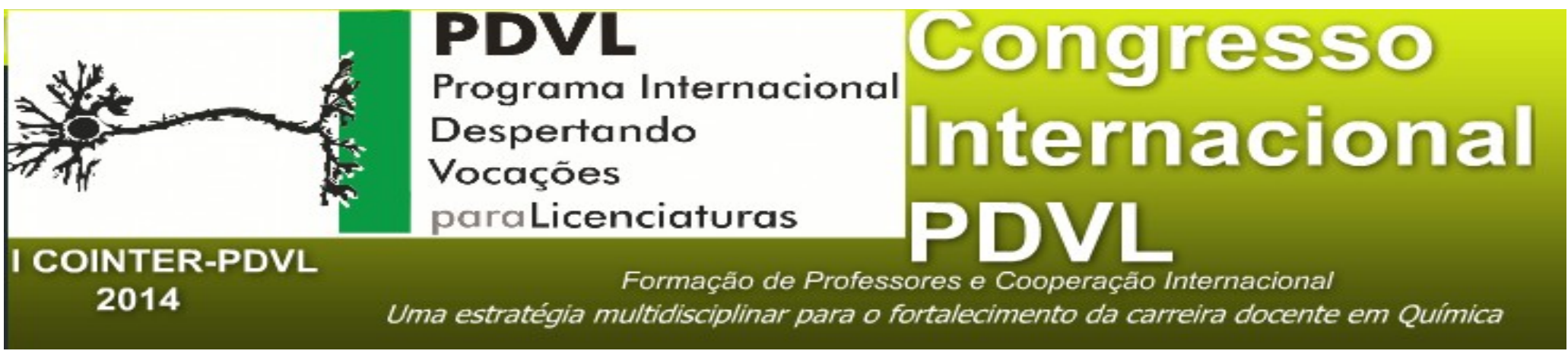

\title{
APLICAÇÃO DE JOGOS LÚDICOS PARA O ENSINO DE QUÍMICA: QUÍMICA NO TABULEIRO “QUÍMICOLEIRO”
}

Apresentação: Pôster

\begin{abstract}
Judiclenia Macedo Santana ${ }^{11}$; Kivia Dulce Fonseca ${ }^{22}$; Marlizia Adja Lopes de Oliveira ${ }^{33}$; Ana Jacinta Dantas Medeiros ${ }^{44}$
\end{abstract}

\section{Introdução}

Ensinar Química principalmente no Ensino Médio, nos dias de hoje ainda é um grande desafio para muitos docentes, sabendo disto vemos que há uma grande dificuldade por parte dos docentes que não conseguem atingir certos objetivos educacionais propostos e uma desmotivação entre os alunos, que consideram a química uma disciplina difícil e que exige muita memorização. A cada dia mais, o valor do jogo na educação tem oscilado. Na atualidade em momentos de crítica e de reformulação da educação, os jogos são lembrados cada vez mais, e vem ganhando a cada dia mais espaço e sendo usado como alternativas capazes de solucionar problemas das práticas pedagógicas.

O presente trabalho tem como objetivo fazer um levantamento de como anda o processo de aprendizagem dos alunos, na disciplina de Química onde foi elaborado e aplicado um jogo de tabuleiro composto por diversas perguntas dos assuntos de Química que é abordado no $1^{\circ}$

1 Licenciatura Plena em Química/IFRN/judiclenia_ms@hotmail.com

2 Licenciatura Plena em Química/IFRN/kiviadulce@hotmail.com

3 Licenciatura Plena em Química/IFRN/marlizia.oi@hotmail.com

4 Licenciatura Plena em Química/IFRN/anna.medeiros@ifrn.edu.br 
ano do ensino médio, esse tabuleiro foi composto por 3 níveis de dificuldade: fácil, médio e difícil. Com isso foi feito uma revisão bibliográfica para comprovar a importância de sua aplicação no ensino médio, como forma de auxiliar os alunos para que possam sair da monotonia do giz e da lousa e terem um melhor desempenho na disciplina, já que os jogos lúdicos são ferramentas importantes no ensino e aprendizagem de química. Posteriormente será feito levantamentos de dados sobre o nível que se encontra a disciplina de química na escola que será realizada a aplicação do jogo.

\section{Fundamentação Teórica}

Ao se aplicar o jogo dentro da educação, é possível que alguém se deixe levar por um pensamento errôneo, chegando até a pensar que o jogo e a educação caminham lado a lado, porém sem que o jogo seja usado com fins pedagógicos.

Segundo Cunha (1998), Gomes e Friedrich (2001), Kishimoto (1996) o jogo pedagógico ou didático tem como objetivo proporcionar determinadas aprendizagens, diferenciando-se do material pedagógico, por conter o aspecto lúdico e por ser utilizado para atingir determinados objetivos pedagógicos, sendo uma alternativa para melhorar o desempenho dos estudantes em alguns conteúdos de difícil aprendizagem. De acordo com Kishimoto (1994), o jogo, considerado um tipo de atividade lúdica, possui duas funções: a lúdica e a educativa. Onde elas devem estar em equilíbrio, pois se a função lúdica prevalecer, não passará de um jogo e se a função educativa for predominante será apenas um material didático. Um dos objetivos da atividade lúdica é propiciar o meio para que o aluno induza o seu raciocínio, a reflexão e posteriormente a construção do seu conhecimento promovendo a construção do conhecimento cognitivo, físico, social e psicomotor o que o leva a memorizar mais facilmente o assunto abordado, com isso, desenvolvendo as habilidades necessárias às práticas educacionais da atualidade.

\section{Metodologia}

O propósito do Trabalho é utilizá-lo como um jogo educativo para facilitar a construção de conceitos relacionados à química geral (matéria e suas transformações, a constituição da matéria, tabela periódica, interações atômicas e moleculares) abordado, geralmente, na $1^{\text {a }}$ serie do Ensino Médio e pode ser utilizado por no máximo 20 alunos por vez, dividido em 4 grupos. A atividade lúdica desenvolvida na forma de tabuleiro é semelhante ao jogo comercializado, entretanto, o modelo foi adaptado para as finalidades educativas, relacionando com as disciplinas de Química. O Jogo Didático é similar a um Jogo de Tabuleiro comum. Foi utilizado como banco de dados 50 cartas, com cinco cores diferentes equivalentes aos diversos níveis de dificuldade das perguntas que 
eram dirigidas aos participantes. As cores foram divididas da seguinte forma: a cor laranja e rosa representava o nível de dificuldade fácil, as cores azul e verde representavam o nível intermediário, e por fim a cor amarela que representava o nível difícil. O processo de como se jogar no Químicoleiro era o seguinte: divide os participantes em 5 grupos compostos por 3 ou 5 pessoas. Cada equipe escolhe um líder e cada líder vai jogar o dado. O que conseguir a maior pontuação no dado começa a jogar e os demais seguem a ordem dos que efetuaram a pontuação maior do dado o primeiro grupo joga o dado olha a numeração em que caiu no tabuleiro, puxa-se a cartinha na referida cor que parou e se responder a pergunta que esta na carta corretamente avança nas casas, se errar permanece onde está, ou outros seguem o mesmo procedimento, até que o primeiro chegue ao troféu simbolizando a vitória do tabuleiro. Em todas as casas, os jogadores devem responder as perguntas relacionadas as matérias correspondentes indicadas pelos níveis das cores.

\section{Resultados e Discussões}

O desenvolvimento do Químicoleiro serviu de grande importância para despertar uma atenção a mais dos alunos em relação aos conteúdos de química estudados no $1^{0}$ ano, além de proporcionar prazer na fixação dos conteúdos estudados em sala de aula, estingou-se a participação dos alunos e um grande interesse. O Químicoleiro foi aplicado em turmas do primeiro ano do IFRN - Campos Ipanguaçu. A aplicação do jogo serviu para que os alunos demonstrassem o que haviam absorvido dos conteúdos ministrados pelo professor em sala de aula, em cada cartinha do jogo havia questões referentes aos conteúdos que o professor já havia dado a eles. Com isso o método do jogo serviu como uma revisão para eles, e que o professor atribuiu uma pequena nota para a equipe ganhadora. Durante o jogo foi feito observações, para ver quais os assuntos em que os alunos sentiam mais dificuldades, para com isso posteriormente ser feito levantamentos a serem discutidos com os professores orientando-os a dar uma atenção a mais quando for tratar destes assuntos que eles sentiram maior dificuldade. Diante disto foi confeccionado um gráfico em formato de pizza mostrando os assuntos que eles sentiram, mas facilidade de responder e os que eles sentiram mas dificuldade, e a quantidade de erros e acertos do total das 50 cartinhas.

\section{Conclusões}

A utilização de jogos educativos e de grande importância para o ensino e aprendizagem, tendo com ênfase a prática de jogos didáticos ou atividades lúdicas dentro da sala de aula. Os recursos didáticos são ferramentas fundamentais para o processo de ensino e aprendizagem no qual o jogo didático e caracterizado como uma importante e viável alternativa para auxiliar em tais processos e favorecer a construção do conhecimento do aluno. 


\section{Referências}

CUNHA, H. S. (1998). Brinquedo, desafio e descoberta. $1^{a}$ edição. FAE/MEC/RJ.

GOMES, R. R. E FRIEDRICH, M. A. (2001). Contribuições dos jogos didáticos na aprendizagem de conteúdos de Ciências e Biologia. Em: Rio de Janeiro, Anais, EREBIO, 1, 38992. KISHIMOTO, T. M. (1996). Jogo, Brinquedo, Brincadeira e a Educação. São Paulo: Cortez, 183p.

KISHIMOTO, Tizuko Morchida. O jogo e a educação infantil. São Paulo: Pioneira, 1994 